\title{
Abordagem sobre a Schistosoma Mansoni e seu perfil epidemiológico nos munícipios do Rio Grande do Norte/RN
}

A esquistossomose é uma doença infecto-parasitária causada por protozoários, habitantes de lagos, córregos e açudes, lugares comuns de seu habitat. Este estudo aborda o conceito do Schistosoma mansoni, bem como analisa o perfil epidemiológico dos infectados no período de 2016 a 2017 , no estado do Rio Grande do Norte/RN, com dados disponibilizados no DATASUS. Em 2016 foram notificados 27 casos positivos de esquistossomose e no ano de 2017 , foram 23 casos, em zona rural e urbana. Indivíduos do sexo feminino foram acometidos pela esquistossomose, em 2016, com $29,62 \%$ dos casos e, em 2017 , com $56,52 \%$ dos casos. Os indivíduos do sexo masculino, em 2016, foram acometidos numa porcentagem de 70,37\% dos casos e, em 2017, numa proporção de $43,47 \%$ dos casos. A faixa etária mais infectada em 2016 e 2017 foi a de 20-39 anos, a população menos escolarizada também é a mais atingida sendo a de 5a a 8a série incompleta do ensino fundamental. A esquistossomose ainda permanece infectando comunidades insalubres na Região Nordeste, em específico no estado do Rio Grande do Norte/RN.

Palavras-chave: Esquistossomose; Epidemiologia; Saúde Pública; Barriga D’água.

\section{Approach to Schistosoma Mansoni and its epidemiological profile in the municipalities of Rio Grande do Norte/RN}

Schistosomiasis is an infectious-parasitic disease caused by protozoa, inhabitants of lakes, streams and dams, common places in their habitat. This study addresse the concept of Schistosoma mansoni, as well as analyzes the epidemiological profile of those infected in the period from 2016 to 2017 , in the state of Rio Grande do Norte / RN, with data available in DATASUS. In 2016, 27 positive cases of schistosomiasis were reported and in 2017, there were 23 cases, in rural and urban areas. Female individuals were affected by schistosomiasis in 2016 , with $29.62 \%$ of cases and, in 2017 , with $56.52 \%$ of cases. In 2016 , male individuals were affected in a percentage of $70.37 \%$ of cases and, in 2017 , in a proportion of $43.47 \%$ of cases. The most infected age group in 2016 and 2017 was $20-39$ years old, the less educated population is also the most affected, being the 5th to 8 th grade of elementary school incomplete. Schistosomiasis still continues to infect unhealthy communities in the Northeast, specifically in the state of Rio Grande do Norte/RN.

Keywords: Schistosomiasis; Epidemiology; Public health; Water belly.

Topic: Epidemiologia

Reviewed anonymously in the process of blind peer
Received: 16/08/2019

Approved: 19/01/2020
Adriano Menino de Macedo Junior Centro Universitário Natalense, Brasil http://lattes.cnpq.br/4134152465913204 http://orcid.org/0000-0001-6367-1088 adrianomenino2016@gmail.com

Alani Brasil da Silva Costa

Centro Universitário Natalense, Brasil http://lattes.cnpq.br/3171392678259940

http://orcid.org/0000-0002-8733-0381 alaneppsilva@hotmail.com

\section{Referencing this:}

MACEDO JUNIOR, A. M.; COSTA, A. B. S.. Abordagem sobre a Schistosoma Mansoni e seu perfil epidemiológico nos munícipios do Rio Grande do Norte/RN. Medicus, v.2, n.1, p.7-13, 2020. DOI: http://doi.org/10.6008/CBPC2674-6484.2020.001.0002 


\section{INTRODUÇÃO}

A esquistossomose é uma doença infecto-parasitária causada pelos platelmintos, seu agente etiológico é Schistosoma, a Schistosoma mansoni e Schistosoma japonicum, que afeta o trato gastrintestinal, enquanto a Schistosoma haematobium afeta o trato urinário, conhecida popularmente como barriga d'água, febre do caramujo ou bilharzíaze (TERRA et al., 2018). A origem da disseminação do gênero Schistosoma está ligada diretamente a um navio negreiro de imigrantes orientais e asiáticos, que chegou às Américas trazendo tripulantes que estavam infectados com o parasita. No Novo Mundo, o clima tropical favoreceu o estabelecimento da Schistosoma mansoni (TERRA et al., 2018).

A infecção parasitaria é favorecida por diversos fatores, dentre eles temos: fatores biológicos, demográficos, socioeconômicos, políticos e culturais. Tais fatores contribuem para o surgimento das endemias, sobretudo em regiões tropicais que acabam sendo as mais atingidas. Em países subdesenvolvidos, a falta de saneamento básico, de sistema de descartes de dejetos impróprios aliado a um sistema de tratamento de águas com maus condições ou inexistentes favorecem o contato da pessoa com águas contaminadas, aumentando a prevalências da endemia (OLIVEIRA et al., 2019).

Existem seis espécies de Schistosoma que podem causar a esquistossomose no homem: $\mathrm{S}$. hematobium, S. intercalatum, S. japonicum, S. malayensis, S. mansoni e S. mekongi. Destas, apenas S. mansoni é encontrada no continente americano. Esse parasita tem os caramujos como seu hospedeiro intermediário, que podem contaminar rios e lagos. Pessoas que entram em contato com as águas contaminadas são infectadas pelas metacercárias dos parasitas que penetram avidamente na pele e nas mucosas ou, quando ingeridos por meio de alimentos contaminados, penetram nas mucosas antes de chegar no estômago e ser destruídos pelo suco gástrico (OLIVEIRA et al., 2019).

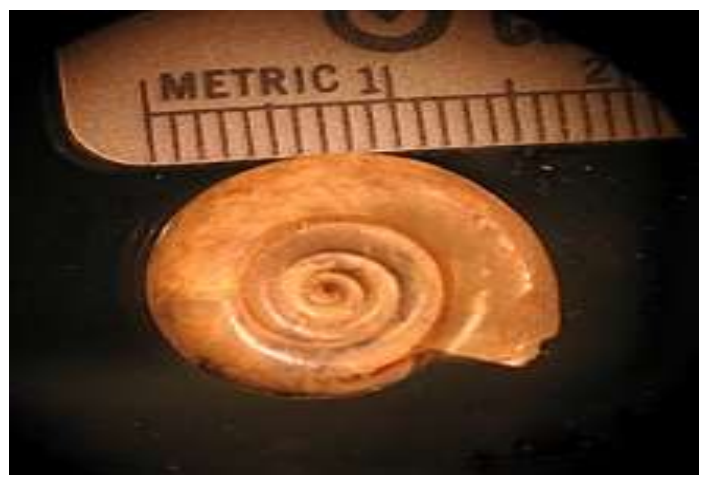

Figura 1: Biomphalaria glabrata, caramujo hospedeiro intermediário de S. mansoni. ${ }^{1}$

Para a propagação da esquistossomose acontecer, é necessário existir o caramujo de espécie Biomphalaria glabrata, já que é o hospedeiro intermediário do Schistosoma mansoni. O ciclo de contágio se dá quando as fezes excretadas pelos humanos (hospedeiro definitivo) são lançadas nos lugares impróprios onde tem água. Depois de um certo tempo, os ovos do S. mansoni, liberando a larva ciliada, chamada de miracídio, vão eclodir e contaminar o molusco. Essas larvas saem do caramujo em torno de quatro a seis semanas, ficam dispersas e livres na água na forma de cercárias, infectando o homem que entrar em contato

${ }^{1}$ https://www.cdc.gov/dpdx/schistosomiasis/index.html 
com a água, causando a infecção, o verme se desenvolve dentro de seis semanas (CAMPOS et al., 2019).

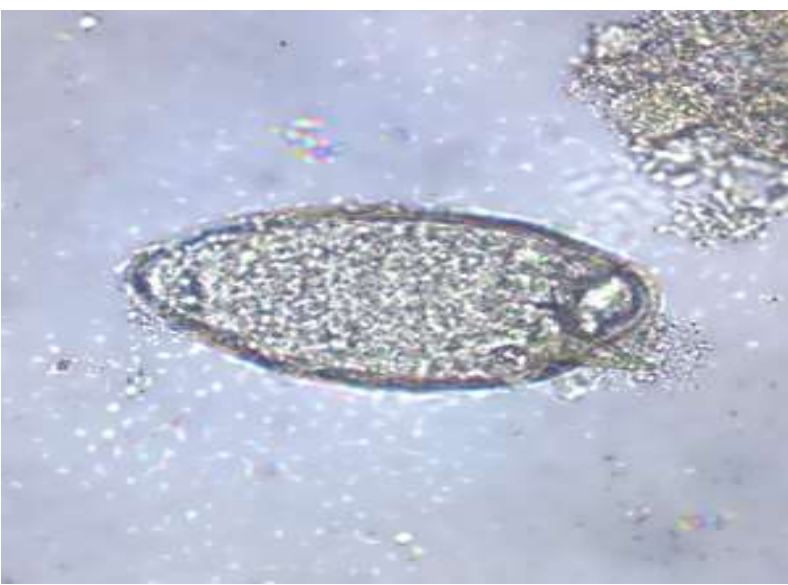

Figura 1: Ovo de S. mansoni em uma montagem úmida não manchada. ${ }^{2}$

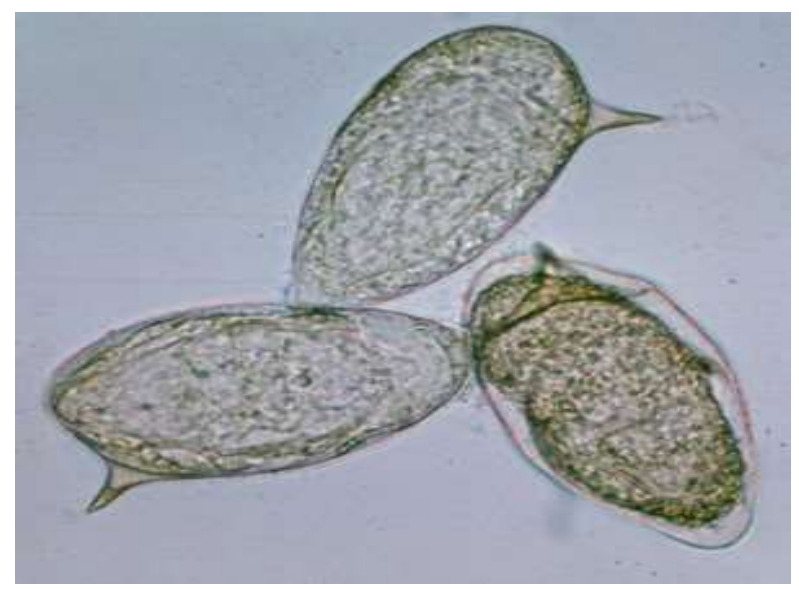

Figura 2: Ovos de S. mansoni em uma montagem úmida e sem manchas. ${ }^{3}$

O homem pode excretar ovos férteis de S. mansoni pelo período de cinco a vinte anos. Os caramujos, por sua vez, continuam liberando cercárias por muitas semanas. As cercárias tem a estimativa de dois dias de vida, pois as mesmas precisam de um hospedeiro, sua capacidade de causar infecção se reduz a cada dia em que a mesma fica dispersa ao ar livre (CAMPOS et al., 2019; MARTINS et al., 2017).

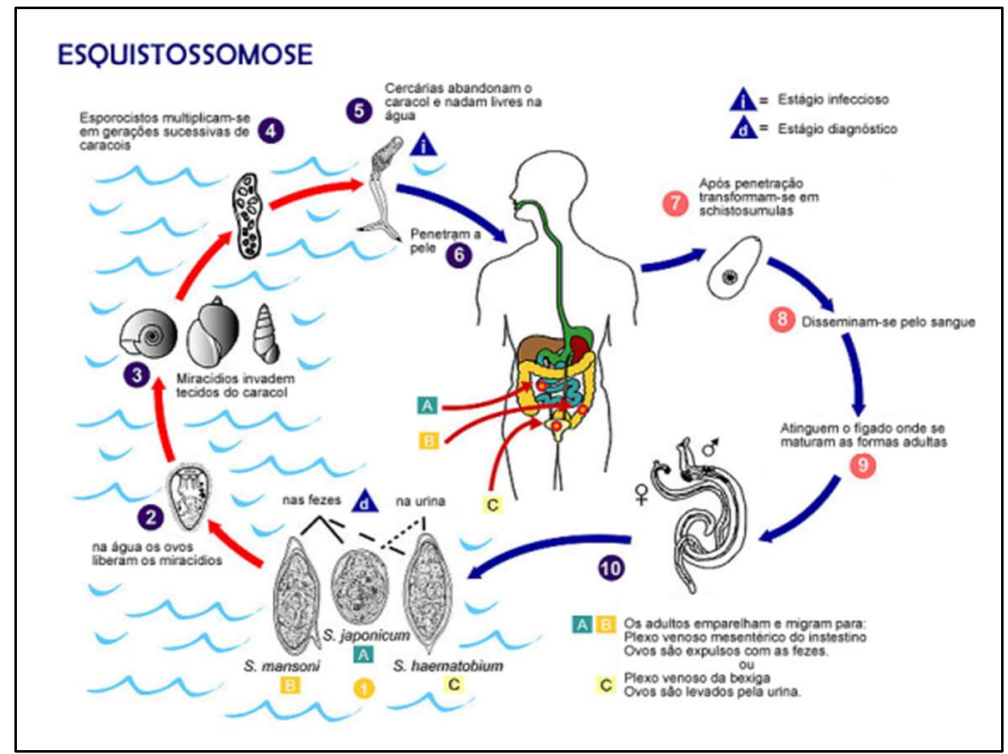

Figura 1: Esquematização do Ciclo biológico de Schistosoma mansoni, agente etiológico da esquistossomose. ${ }^{4}$

Este estudo objetiva relatar os dados de pessoas acometidas por esquistossomose, afim de manter as autoridades públicas em alerta sobre o perfil epidemiológico da doença presente no estado do Rio Grande do Norte, no ano 2019.

\section{MATERIAIS E MÉTODOS}

Esta pesquisa foi desenvolvida, de forma descritiva e retrospectiva, com natureza epidemiológica,

\footnotetext{
${ }^{2}$ https://www.cdc.gov/dpdx/schistosomiasis/index.html

${ }^{3}$ https://www.cdc.gov/dpdx/schistosomiasis/index.html

${ }^{4}$ https://www.cdc.gov/dpdx/schistosomiasis/index.html
} 
com dados fornecido e extraídos da base, de dados do Sistema Nacional de Agravos de Notificação (SINAN), estatísticas essas disponibilizadas pelo DATASUS. Os dados foram filtrados na plataforma pelos anos de 2016 e 2017, para os casos notificados positivos para a Esquistossomose nos municípios do estado do Rio Grande do Norte, localizado na região Nordeste do Brasil. As variáveis avaliadas na discussão foram zona de residência rural e urbana, sexo, faixa etária de pessoas e casos confirmados em mulheres grávidas.

A metodologia da presente pesquisa utilizou também pesquisas bibliográficas, como revisão de literatura, a qual foi lastreada em artigos constantes na base eletrônica SciELO, Google acadêmico, Pubmed, MEDLINE (National Library of Medicine, USA - NLM), assim como repositórios de universidades públicas e privadas, empregando-se as palavras chave: esquistossomose, Saúde pública, perfil epidemiológico, parasitas. Todos os dados epidemiológicos coletados para análise foram selecionados e obtidos por meio do aplicativo TABNET, a partir de suas caixas de opções (linha, coluna e conteúdo). Por se tratar de dados secundários de um banco de domínio público, não foi necessário submeter o trabalho ao Comitê de Ética em Pesquisa em Seres Humanos (CEP).

\section{RESULTADOS E DISCUSSÃO}

A esquistossomose é uma doença endêmica no Brasil, se constituindo como um problema de saúde pública. A doença atinge principalmente as regiões nordeste e sudeste, onde os casos são mais notificados e a transmissão está ligada diretamente ao seu vetor, os moluscos. Foram observados 167 munícipios do estado do Rio Grande do Norte, no qual, no ano de 2016, foram confirmados $2 \%$ do total desses munícipios com casos positivos, são eles: Natal, Goianinha, Várzea, São José de Mipibu e Nova Cruz.

Já no ano de 2017, o percentual de casos confirmados foi de $5 \%$ distribuídos nos municípios de Natal, Pedro Velho, Goianinha, Ceará-mirim, São Paulo do Potengi, Santa Cruz, Rio do Fogo, Extremoz e Caiçara do Norte. As tabelas 1 e 2, mostram os frequentes casos confirmados da esquistossomose mansoni, por zona de residência, segundo os municípios, nos anos de 2016 e 2017.

Tabela 1: notificações de casos em 2016, por zona de Residência, segundo munícipio.

\begin{tabular}{|l|l|l|l|}
\hline Munícipio de notificação & Zona urbana & Zona rural & Total \\
\hline Natal & 22 & - & 22 \\
\hline Goianinha & 1 & 1 & 2 \\
\hline Várzea & - & 1 & 1 \\
\hline São José do Mipibu & - & 1 & 1 \\
\hline Nova Cruz & 1 & - & 1 \\
\hline Total & 24 & 3 & 27 \\
\hline
\end{tabular}

Fonte: SINAN (2020).

Tabela 2: notificações de casos em 2017, por zona de Residência, segundo munícipio.

\begin{tabular}{|l|l|l|l|l|}
\hline Munícipio de notificação & Ignorado/Branco & Zona urbana & Zona rural & Total \\
\hline Natal & 1 & 12 & 1 & 14 \\
\hline Pedro Velho & - & 1 & 3 & 4 \\
\hline Goianinha & - & - & 2 & 2 \\
\hline Ceará-Mirim & - & 1 & 1 & 2 \\
\hline Rio do Fogo & - & - & 1 & 1 \\
\hline Total & 1 & 14 & 8 & 23 \\
\hline
\end{tabular}

Fonte: SINAN (2020). 
Os fatores de riscos pela variável zona de residência rural e urbana estão ligados diretamente à forma de como a população dessas regiões se comporta frente à situação endêmica. Constatamos que o maior número de infectados foi na cidade de Natal, capital do RN, onde em 2016 o número de casos confirmados para a esquistossomose foi de 22, já no ano de 2017 foram confirmados 14 casos positivos para o parasita. Um estudo também realizado na Região Nordeste, no estado da Paraíba, no período de 2015 e 2017 , notificou 38 munícipios com casos de esquistossomose, sendo no munícipio de Pedras de Fogo o maior número de casos, totalizando 29\% do total dos municípios investigados (PEREIRA et al., 2018).

Sabe-se que a região Nordeste é a mais acometida por doenças endêmicas, pois a região sofre frequentemente com condições inadequadas de saneamento Básico, a população não dispõe de ações educativas em saúde, ainda há um alto índice de pobreza, fatores que contribuem para a disseminação de formas parasitárias, já que pessoas que são vítimas da desigualdade social e econômica acabam sendo mais suscetíveis a determinados problemas de saúde pública (SANTOS et al., 2018). A esquistossomose é uma infecção que atinge tantas pessoas do sexo masculino como do sexo feminino. Nesse estudo elaborado, a variável apresentou diferença se comparando os anos de 2016 e 2017, como podemos ver nas tabelas 3 e 4, a seguir:

Tabela 3: notificações de casos em 2016, por sexo, segundo munícipio.

\begin{tabular}{|l|l|l|l|}
\hline Município de notificação & Sexo masculino & Sexo feminino & Total \\
\hline Natal & 15 & 7 & 22 \\
\hline Goianinha & 2 & - & 2 \\
\hline Várzea & 1 & - & 1 \\
\hline São José de Mipibu & 1 & - & 1 \\
\hline Nova Cruz & - & 1 & 1 \\
\hline Total & 19 & 8 & 27 \\
\hline
\end{tabular}

Fonte: SINAN (2020).

Tabela 4: notificações de casos em 2016, por sexo, segundo munícipio.

\begin{tabular}{|l|l|l|l|}
\hline Município de notificação & Sexo masculino & Sexo feminino & Total \\
\hline Natal & 6 & 8 & 14 \\
\hline Pedro Velho & 2 & 2 & 4 \\
\hline Goianinha & 1 & 1 & 2 \\
\hline Ceará-Mirim & 1 & 1 & 2 \\
\hline Rio do fogo & - & 1 & 1 \\
\hline Total & 10 & 13 & 23 \\
\hline
\end{tabular}

Fonte: SINAN (2020).

No ano de $2016,29,62 \%(n=8)$ dos casos notificados foram do sexo feminino e $70,37 \%(n=19)$ dos casos foram do sexo masculino; enquanto que no ano de 2017, as variáveis quase não tiveram alteração de casos notificados para esquistossomose, mulheres somaram $56,52 \%(n=13)$ dos casos, já nos homens o percentual foi de $43,47 \%(n=10)$.

Um estudo observacional, descritivo, quantitativo e transversal, realizado na região norte do Brasil, no estado do Pará, no período de 2014 a 2017, revelou que os homens que estavam com a esquistossomose somavam o total de 39 casos, e mulheres 29 casos (PEREIRA, 2019). A esquistossomose é uma doença que acomete o indivíduo humano em qualquer ciclo da vida, podendo assim atingir todas as idades. As tabelas 5 e 6 a seguir, evidenciam os casos confirmados da doença nos municípios do Rio Grande do Norte, classificados por faixa etária: 
Tabela 5: notificações de casos em 2016, por faixa etária, segundo munícipio.

\begin{tabular}{|l|l|l|l|l|}
\hline Município de notificação & $20-39$ & $40-59$ & $70-79$ & Total \\
\hline Natal & 12 & 10 & - & 22 \\
\hline Goianinha & 1 & - & 1 & 2 \\
\hline Várzea & - & 1 & - & 1 \\
\hline São José do Mipibu & - & 1 & - & 1 \\
\hline Nova Cruz & - & 1 & - & 1 \\
\hline Total & 13 & 13 & 1 & 27 \\
\hline
\end{tabular}

Fonte: SINAN (2020).

Tabela 6: notificações de casos em 2017, por faixa etária, segundo munícipio.

\begin{tabular}{|l|l|l|l|l|l|l|l|l|l|}
\hline Município de notificação & $5-9$ & $10-14$ & $15-19$ & $20-39$ & $40-59$ & $60-64$ & $65-69$ & $70-79$ & Total \\
\hline Natal & 1 & - & 1 & 5 & 3 & 2 & 1 & 1 & 14 \\
\hline Pedro Velho & - & - & - & 2 & 1 & - & - & 1 & 4 \\
\hline Goianinha & - & - & - & 1 & - & - & - & 1 & 2 \\
\hline Ceará-Mirim & - & - & - & - & - & - & 1 & 1 & 2 \\
\hline Rio do fogo & - & 1 & - & - & - & - & - & - & 1 \\
\hline Total & 1 & 1 & 1 & 8 & 4 & 2 & 2 & 4 & 23 \\
\hline
\end{tabular}

Fonte: SINAN (2020).

Como podemos observar, a esquistossomose atingiu várias faixas etárias no ano de 2017, representando $54 \%$ do total, comparado com o ano de 2016 , que atingiu $46 \%$ do total de notificações. Esse total não foi muito diferente de um para o outro ano, revelando uma maior frequência ilustrada na faixa etária dos 20 aos 39 anos, quando, em 2016, foi notificada com 48,14\% do total de casos, e em 2017, com $34,78 \%$ do total de casos.

Uma pesquisa transversal e descritiva, de abordagem quantitativa, na Região Nordeste, observando os casos localizados no munícipio de Xexéu/PE, de 2013 a 2015, analisou as faixas etárias dos casos notificados, destacando uma frequência maior em crianças de 0 a 11 anos, representando 22.85\% (n=109), do total de casos e os indivíduos de 12 a 18 anos, com 24,73\% ( $n=118$ ) do total de casos estudados (SILVA et al., 2019). Essas crianças podem ter adquirido a doença através de métodos de higiene e práticas de assepsias impróprias, acarretando insegurança para a saúde dessas pessoas (SILVA et al., 2019). A esquistossomose não tem relação direta com o grau de instrução do indivíduo, mas podemos ver que a população mais contaminada é a menos escolarizada, como podemos ver nas tabelas 7, que demonstra como a esquistossomose infecta o estado do Rio Grande do Norte, segunda a variável escolaridade:

Tabela 7: notificações de casos em 2016 e 2017, por faixa etária, segundo munícipio.

\begin{tabular}{|l|l|l|}
\hline Escolaridade & Casos notificados em 2016 & Casos notificados em 2017 \\
\hline Ignorado/Branco & 8 & 8 \\
\hline Analfabeto & 2 & 4 \\
\hline 1a a 4a série incompleta do ensino fundamental & 4 & 1 \\
\hline 4a série completa do ensino fundamental & 1 & 1 \\
\hline 5a a 8a série incompleta do ensino fundamental & 2 & 4 \\
\hline Ensino fundamental completo & - & 1 \\
\hline Ensino médio incompleto & 2 & 1 \\
\hline Ensino médio completo & 3 & 1 \\
\hline Educação superior incompleto & 2 & - \\
\hline Educação superior completo & 2 & - \\
\hline Não se aplica & - & 1 \\
\hline Total & 26 & 22 \\
\hline
\end{tabular}

Fonte: SINAN (2020).

As populações que tiveram maiores notificações de esquistossomose foram as de $\geq 5 \underline{\text { a }}$ a 8a $^{\text {série }}$ 
incompletas do ensino fundamental. Dentro desse contexto podemos alegar que a falta de conhecimentos sobre o parasita, advinda de uma deficiência em educação sobre o meio-ambiente, resulta na transmissão da doença. Nesse caso, estratégias de educação em saúde devem ser adotadas, para determinados locais em que o nível de educação é mais baixo.

Um estudo descritivo e retrospectivo, com abordagem quantitativa, com base nos prontuários dos portadores de esquistossomose, na Região Nordeste, no munícipio de Bom Jardim/PE, nos anos de 2013 a 2014, apontou que as pessoas com até o 2a grau completo e incompleto foram as mais afetadas pelo microrganismo (SILVA et al., 2019).

\section{CONCLUSÕES}

O presente estudo expõe os fatos coletados de notificações positivas para a Schistosoma mansoni, destacando como as condições precárias de higiene, a ausência de saneamento básico, e o fato de termos uma saúde pública em péssimas condições acabam por se tornar fatores que contribuem com a crescente endemia da esquistossomose. Aliado a isso, vê-se que a população menos escolarizada também acaba sendo a mais acometida pela doença, levando em consideração a pouca educação sobre o assunto. Nesse sentido, destacamos que medidas de educação ambiental devem ser adotadas pelas unidades de atenção básicas, bem como a implementação de políticas de saúde pública pelas autoridades de cada munícipio, sobretudo daqueles onde a esquistossomose ainda é considerada um problema de saúde pública.

\section{REFERÊNCIAS}

CAMPOS, S. D. S.; LIRA, R. G. D.; SILVA, E. C. D.. Medidas de prevenção da esquistossomose: um estudo teórico. In: SEMANA DE MOBILIZAÇÃO CIENTÍFICA-ALTERIDADE, DIREITOS FUNDAMENTAIS E EDUCAÇÃO. Anais. 2019.

MARTINS, G. C.; SANTOS, C. N.; SILVA, M. V.; ARAUJO, M. C. T.; CAVALCANTI, S. M. L.; RIBEIRO, K. R. C.. Intervenções do enfermeiro na prevenção da esquistossomose mansoni. Revista Saúde, v.11, n.1, p.32, 2018.

OLIVEIRA, J. L.; SOUZA, R. F.; EMERICK, G. B.; TEIXEIRA FILHO, R. R.; SILVA, J. S.. Logística desenvolvida do ESF em lidar com a doença endêmica esquistossomose. In: SEMINÁRIO CIENTíFICO DO UNIFACIG, 4. Anais. 2019.

PEREIRA, G. S.; OLIVEIRA, H. M. B. F.; OLIVEIRA FILHO, A. A.. Educação ambiental em saúde: análise dos casos de esquistossomose notificados na paraíba no período de 2015 a 2017. Números, v.64, n.17, 2018.

PEREIRA, L. F. S.. Epidemiological profile of mansonic schistosomiasis of 2014 to 2017 in the state of Pará. Brazilian Journal of Health Review, v.2, n.2, p.14011407, 2019.
SANTOS, C. M. A.; OLIVEIRA SANTOS, L. S.; SANTOS, J. A.; SILVA, E. S.; SANTOS, M. H.; SILVA, D. K.; SANTOS, C. B.. Comparativo e perfil dos infectados em esquistossomose no estado de Alagoas entre 2016 e 2017. PUBVET, v.13, n.153, 2019.

SILVA, J. D. R., ROCHA, T. J. M.. Frequência de helmintos segundo os dados do programa de controle da esquistossomose no município de Xexéu, Pernambuco. Journal of Health \& Biological Sciences, v.7, n.3, p.253-257, 2019.

SILVA, M. B. A.; GOMES, B. D. M. R.; LOPES, K. A. M.; MEDEIROS, C. A.; BRITO, M. I. B. S.. Perfil clínicoepidemiológico de indivíduos portadores de esquistossomose em um município prioritário de Pernambuco. Revista Saúde \& Ciência, v.8, n.1, p.76-87, 2019.

TERRA, M. R.; SILVA, R. S.; GONÇALVES, C. D. S. F.; PEREIRA, J. A. R.; ZANARDO, J.. Levantamento Epidemiológico de Esquistossomose Mansoni em Londrina/PR. Revista Uningá, v.55, n.3, p.208-217, 2018.

A CBPC - Companhia Brasileira de Produção Científica (CNPJ: 11.221.422/0001-03) detém os direitos materiais desta publicação. Os direitos referem-se à publicação do trabalho em qualquer parte do mundo, incluindo os direitos às renovações, expansões e disseminações da contribuição, bem como outros direitos subsidiários. Todos os trabalhos publicados eletronicamente poderão posteriormente ser publicados em coletâneas impressas sob coordenação da Cognitionis Publishing, da Companhia Brasileira de Produção Científica e seus parceiros autorizados. Os (as) autores (as) posteriormente ser publicados em coletâneas impressas sob coordenação da Cognitionis Publishing, da Companhia Brasileira de Produção Cientifica e seus parce
preservam os direitos autorais, mas não têm permissão para a publicação da contribuição em outro meio, impresso ou digital, em português ou em tradução. 